\title{
Differences between Judo, Taekwondo and Kung-fu Athletes in Sustained Attention and Impulse Control
}

\author{
Javier Sánchez-López ${ }^{1}$, Thalía Fernández ${ }^{1 *}$, Juan Silva-Pereyra ${ }^{2}$, \\ Juan Antonio Martínez Mesa ${ }^{3}$ \\ ${ }^{1}$ Departamento de Neurobiología Conductual y Cognitiva, Instituto de Neurobiología, Universidad Nacional \\ Autónoma de México, Querétaro, México \\ ${ }^{2}$ Proyecto de Neurociencias, Facultad de Estudios Superiores Iztacala, Universidad Nacional Autónoma de \\ México, Estado de México, México \\ ${ }^{3}$ Instituto de Medicina del Deporte de Cuba, Habana, Cuba \\ Email: "thaliafh@yahoo.com.mx
}

Received April 18 $8^{\text {th }}, 2013$; revised May 21 $1^{\text {st }}, 2013$; accepted June $19^{\text {th }}, 2013$

Copyright (C 2013 Javier Sánchez-López et al. This is an open access article distributed under the Creative Commons Attribution License, which permits unrestricted use, distribution, and reproduction in any medium, provided the original work is properly cited.

\begin{abstract}
Attention processes are essential in athletic performance. Competition in combat sports requires high levels of attention, concentration and self-control. The aim of this study was to determine the differences in attention test performance among three groups of athletes from different disciplines of martial arts (judo, taekwondo and kung-fu). Twenty athletes with at least one year of experience in their respective sport were included in the study. The Test of Variables of Attention (TOVA) was performed, and data for the standard and $\mathrm{Z}$ scores of the quarters, halves and totals of each variable were analysed. The kung-fu athletes showed better inhibition response than the judo and taekwondo athletes. Minor performance deterioration during the impulsivity test was identified in kung-fu athletes compared with taekwondo and judo athletes. Judo athletes showed higher variability in reaction times than kung-fu athletes. Our study suggests that kung-fu training improved attention skills more than the other two disciplines. This effect can be explained by the athletes' dedication to kung-fu training and the sport's promotion of discipline, self-control and meditation.
\end{abstract}

Keywords: Attention; Martial Arts; Athletes

\section{Introduction}

Athletic performance depends on components such as physical, technical and psychological capacities. Psychological capacities are directly related to cognitive processes, and their synthesis is required for optimal training. Of the cognitive processes involved in athletic performance, attentional processes have been a primary research focus.

Research on cognitive processes has been focused on attention for many years. William James described attention as "taking possession by the mind, in clear and vivid form, of one out of what seem several simultaneously possible objects or trains of thought" (Posner, 2004). Three fundamental features of attention have been established. First, the attention system in the brain is anatomically separate from data-processing systems that are capable of operating on specific inputs, even when the attention is focused elsewhere. In this sense, the attention system is similar to other sensory and motor systems. It interacts with other parts of the brain but maintains its own identity. Second, attention is processed by a network of anatomical areas; it is neither the function of a single centre nor a general function of the brain operating as a whole. Third, the areas involved in attention perform different functions, and these specific computations can be specified in cognitive terms (Posner \&

${ }^{*}$ Corresponding author.
Petersen, 1990).

In the performance of sports, attention is involved at the first stage of psychomotor processes for any planned action, and this stage affects the following stages of mental resolution of special tactics and motor responses (Del-Monte, 2005). In particular, combat athletes focus their attention to improve or maintain positive thoughts and emotions, react to external stimuli, concentrate on their opponent and increase arousal (Anshel \& Payne, 2006). Strategies of fighters include focusing their attention on their own performance and the performance of their opponent, and maintaining their attention to prepare the speed and power of a motor response. Previous studies have reported increased attentional capacities in expert athletes (Abernethy \& Russell, 1987; Williams \& Grant, 1999).

Martial arts are combat sports. In contrast to other sports, they involve more than physical and mechanical phenomena because the spirit is as important as the body. The techniques of each gestural movement contain real and symbolic significance; these movements have religious and philosophical meaning (Rodríguez, 2003). In the particular case of these disciplines, the athlete's attention is essential to achieving technical/tactical and competitive development (Anshel \& Payne, 2006). Martial arts competitions require short periods of physical and attentional intensity. From the perspective of information processing, martial arts competitors must be able to anticipate actions and 
strategies of their opponent, quickly perceive stimuli, quickly strategise and make decisions and respond "automatically".

Bottom up and top-down attentional mechanisms are essential for optimum performance in martial arts. The ability to focus and sustain a relevant stimulus and to identify relevant information from peripheral stimuli are the most important mechanisms of attention in this sport. It has been proposed that self-regulation is also an important part of martial arts training and characterizes its practitioners (Lakes \& Hoyt, 2004). This is directly related to the ability of inhibiting the action, which is crucial for accurate performance on tasks requiring response (Burle, Posamai et al. 2002; Ridderinkhof, 2002). Both mechanisms, attention and self-regulation, which are fundamentals in martial arts sports, can be evaluated through a Test of Variables of Attention. This testing allows assessment of sustained attention and impulse control, and was used to evaluate these abilities in our study.

Experts in a particular sport can modulate their attention resources according to specific task demands (Nougier \& Rossi, 1999), and they can use this ability to quickly extract relevant information (Abernethy \& Russell, 1987). Attentional resources were observed to be used differently between karate and volleyball athletes, which means that the psychological configuretions of the athletes depend on their respective sport (Fontani, Lodi, Felici, Migliorini, \& Corradeschi, 2006). However, despite the large amount of evidence linking psychological skills with athletic performance, there is no scientific evidence of a characteristic psychological profile of martial arts athletes (Carazo \& Araya, 2010). The aim of this study was to describe differences in the attentional processes of athletes who practice judo, taekwondo and kung-fu.

We used the Test of Variable of Attention (TOVA) to explore two subcomponents of attention: sustained attention and impulse control. We assert that these subcomponents are involved in the skills of martial arts athletes that these subcomponents are related to the psychological configurations of specific disciplines and that differences exist in attentional abilities among athletes who practice different combat disciplines. Specifically, the aim of this study was to explore differences in performance on an attention test among three groups of athletes who practice judo, taekwondo and kung-fu. Our hypothesis is that differences between groups in sustained attention and impulse control will be found, and these differences will be related to the specific characteristics of disciplines.

\section{Method}

\section{Participants}

Twenty martial arts athletes from three different combat disciplines (judo, taekwondo and kung-fu) with more than one year of experience in each sport were recruited. All participants were healthy (no history of neurological illness), and they had normal or corrected-to-normal vision. All subjects included in the study had scores in the normal range $(>90)$ in the Wechsler Intelligence Scale and an attention deficit and hyperactivity disorder (ADHD) score over -1.80 on the Test of Variables of Attention (TOVA), which suggested normal attentional abilities compared with a normative database.

No differences for age and intelligence quotient were found between groups. Variance in age was considered and controlled using T.O.V.A.'s Z values, which are the scores compared with normative database by age and gender. All participants were informed of their rights and gave informed written consent for their participation in the study. This research was conducted ethically and was approved by the Ethics Committee of the Neurobiology Institute at Universidad Nacional Autónoma de México. Table 1 shows the demographic characteristics of the samples (mean, standard deviation and number of participants).

\section{Test of Variables of Attention}

The TOVA was developed to measure attention and impulse control processes in four areas: response time variability, response time, impulse control (commission errors) and inattention (omission errors). Visually, the stimuli were squares on a screen measuring approximately 3 inches from one corner of the square to its opposite diagonal corner (see Figure 1).

During the visual test, a stimulus was presented for $100 \mathrm{~ms}$ at $2000 \mathrm{~ms}$ intervals. The designated target was presented in $22.5 \%(n=72)$ of the trials during the first half of the test (infrequent stimulus condition) where sustained attention is evaluated, and $77.5 \%(\mathrm{n}=252)$ of the trials during the second half of the test (frequent stimulus condition) which evaluates impulse control. The subject was instructed to respond to the target as quickly as possible. A varying target-nontarget ratio allowed the examination of the effects of differing response demands on response time variability, response time, inattention and impulsivity. Values for each variable are compared with a normative database and are shown for quarters, halves and totals of the test.

Specifically, quarters 1 and 2 represented the first half or infrequent stimulus condition and had 36 targets out of 162 stimuli per quarter (a ratio of 1:3.5). Quarters 3 and 4 represented the second half or frequent stimulus condition and had 126 targets out of 162 stimuli per quarter (a ratio of 3.5:1). The targets were presented in a fixed, random sequence per quarter. The first half of the scores recorded the subject's performance for quarters 1 and 2 combined, and the second half recorded the combined scores for quarters 3 and 4 . The total score reflected

Table 1.

Participants' characteristics in each group.

\begin{tabular}{ccc}
\hline Discipline & Age & Intelligence Quotient \\
\hline Judo & $\mathrm{M}=22$ & $\mathrm{M}=104$ \\
$\mathrm{~N}=8$ & $\mathrm{SD}=8.1$ & $\mathrm{SD}=7.9$ \\
Kung-fu & $\mathrm{M}=23$ & $\mathrm{M}=104$ \\
$\mathrm{~N}=6$ & $\mathrm{SD}=5.2$ & $\mathrm{SD}=10.6$ \\
Taekwondo & $\mathrm{M}=30$ & $\mathrm{M}=108$ \\
$\mathrm{~N}=6$ & $\mathrm{SD}=13.6$ & $\mathrm{SD}=5.9$ \\
\hline
\end{tabular}

Note: $\mathrm{M}=$ mean, $\mathrm{SD}=$ standard deviation.

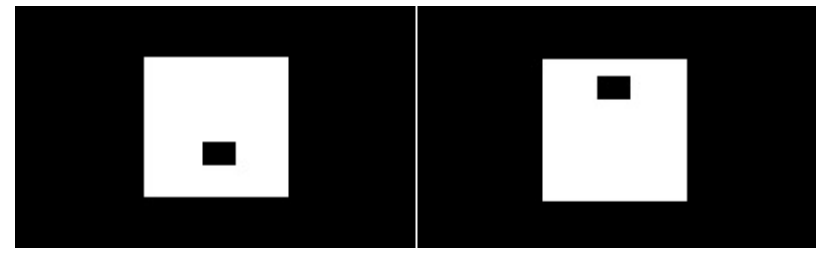

Figure 1.

Visual TOVA stimuli. Right target stimulus and left nontarget stimulus. Figure reprinted from Leark, Greenberg, Kindschi, Dupuy, \& Hughes (2007). 
the subject's performance on the entire test. The total test time was 21.6 minutes, with 10.8 minutes per half and 5.4 minutes for each of the four quarters.

The TOVA software automatically recorded the subject's responses, nonresponses and reaction times and then calculated raw scores and percentages, which eliminated the risk of examiner error. All of the subject's responses and nonresponses for all of the variables throughout the test were recorded, categorised and saved. The software also automatically calculated the standard scores and $\mathrm{z}$ scores for each variable for quarters, halves and totals.

TOVA assesses the following variables: 1) Response Time Variability, which is a measure of the variability in the subject's response time for accurate responses; 2) Response Time, which consists of the average time that it takes for the subject to respond correctly; 3) Errors of Commission, which occur when the subject fails to inhibit the response and incorrectly responds to a nontarget, i.e., the subject presses the button when a nontarget is presented; 4) Errors of Omission, which occur when the subject does not respond to the designated target, i.e., the subject fails to press the button when a target is presented; 5) the d' (D Prime) score, which is a response sensitivity score that reflects the ratio of the hit rate to the "false alarm" rate; and 6) the ADHD score, which is a comparison between the current subject's performance and a normative database. The TOVA has been normed on children and adults, ages 4 to 80 years. All norms are differentiated by age and gender. Ages are calculated by rounding to the nearest birthday within six months (Leark, Greenberg, Kindschi, Dupuy, \& Hughes, 2007).

\section{Procedure}

Participants were seated in a comfortable chair in a room with low light in front of a 12-inch (diagonally measured) monitor with an eye-to-monitor distance of approximately 32 inches. All participants were instructed to respond by pressing a button as rapidly and accurately as possible when the target stimulus appeared and to not press the button when the nontarget stimulus appeared, as programmed in the TOVA. All participants received a previous training block.

\section{Data Analysis}

The sample size was small, and a normal distribution was not guaranteed; thus, parametric analyses were inappropriate. To control for Type I errors, the statistical analysis was performed using the Nonparametric Multivariate Permutation Method (Galan, Biscay, Rodriguez, Perez-Abalo, \& Rodriguez, 1997).

The permutation method allows comparisons between means in small samples. This method is based on the assumption that data from one group or the other are the same, so values can be exchanged; if they are equal, changing values from one condition to another when t-student is calculated should not matter. Successive and multiple permutation allow building an empirical distribution, which includes the maximum or minimum originals without permutation. If a value is significant, it is because the difference was sufficiently large enough to reject the null hypothesis and conclude that the observations of both conditions are different.

Among the advantages of this method are: 1) it does not consider in its assumptions that the variables be distributed in any specific way and 2) the proportion of subjects in relation to the number of variables is not a problem.

The data analysis compared the standard and $\mathrm{Z}$ scores of each variable (response time variability, response time, errors of commission, errors of omission, perceptual sensitivity d' and ADHD score) between groups and took into account the total value of the variable, the values in each half of the test and the values in each quarter of the test. Analyses were performed using the Statistical software Neuronic by Neuronic S.A. de C.V.

\section{Results}

Differences between groups were found in errors of commissions, perceptual sensitivity (d') and response time variability variables. Significant differences are reported.

\section{Errors of Commissions}

Significant differences were found in the total $\mathrm{Z}$ score of commission errors among the groups $(p=.05)$, where kung-fu athletes showed a higher score $(\mathrm{M}=.91, \mathrm{SD}=.27)$ than the taekwondo group $(\mathrm{M}=.078, \mathrm{SD}=.67) . \mathrm{Z}$ score differences were found for both halves of the test. Kung-fu athletes had a higher score $(\mathrm{M}=.89, \mathrm{SD}=.30)$ than judo athletes $(\mathrm{M}=.04$, $\mathrm{SD}=1.03, p=.05)$ on the first half of the test. Similarly, in the second half, kung-fu athletes achieved a higher score $(\mathrm{M}=.85$, $\mathrm{SD}=.32)$ than judo athletes $(\mathrm{M}=-.025, \mathrm{SD}=1.5, p=.03)$ and taekwondo athletes $(\mathrm{M}=-.056, \mathrm{SD}=.64, p=.01)$. An analysis of the quarters for the $\mathrm{Z}$ score of this variable showed differences among the three quarters. In the first quarter, kung-fu athletes had higher scores $(\mathrm{M}=.81, \mathrm{SD}=.41)$ than judo athletes $(\mathrm{M}=-.12, \mathrm{SD}=.95, p=.03)$; in the third quarter, kung-fu athletes had higher scores $(\mathrm{M}=.82, \mathrm{SD}=.28)$ than taekwondo athletes $(\mathrm{M}=-.28, \mathrm{SD}=.61, p=.001)$; and in the fourth quarter, kung-fu athletes had higher scores $(\mathrm{M}=.76, \mathrm{SD}=.36)$ than both the judo $(\mathrm{M}=-.19, \mathrm{SD}=1.6, p=.03)$ and taekwondo $(\mathrm{M}$ $=.11, \mathrm{SD}=.59, p=.04$ ) groups (see Figure 2).

\section{Perceptual Sensitivity (d')}

Differences among groups in the second half were observed for the $\mathrm{Z}$ score of d', where kung-fu athletes had a higher score $(\mathrm{M}=.77, \mathrm{SD}=.66)$ than judo athletes $(\mathrm{M}=-.20, \mathrm{SD}=1.2, p$ $=.05)$. Differences across quarters were also found, and the kung-fu group had a higher score $(\mathrm{M}=.89, \mathrm{SD}=1.22)$ than the taekwondo group $(\mathrm{M}=-.21, \mathrm{SD}=.32)$ in the third quarter $(p$ $=.04)$. In the fourth quarter, kung-fu athletes had higher scores $(\mathrm{M}=.77, \mathrm{SD}=.43)$ than both taekwondo $(\mathrm{M}=-.004, \mathrm{SD}=.48$, $p=.03)$ and judo $(\mathrm{M}=-.36, \mathrm{SD}=1.2, p=.05)$ athletes (see Figure 3).

\section{Response Time Variability}

Judo athletes had higher response time variability than kung$\mathrm{fu}$ athletes. In the first quarter of the test, judo athletes had a higher response time variability $(\mathrm{M}=60.5 \mathrm{~ms}, \mathrm{SD}=20.41)$ than kung-fu athletes $(\mathrm{M}=41 \mathrm{~ms}, \mathrm{SD}=6.5, p=.03)$. During the third quarter, judo athletes showed a higher variability $(\mathrm{M}=$ $68.1 \mathrm{~ms}, \mathrm{SD}=12.47)$ than kung-fu athletes $(\mathrm{M}=54.33 \mathrm{~ms}$, SD $=17.25, p=.01)$ (see Figure 4).

\section{Discussion}

Previous studies on attention in athletes have investigated 


\section{J. SÁNCHEZ-LÓPEZ ET AL.}

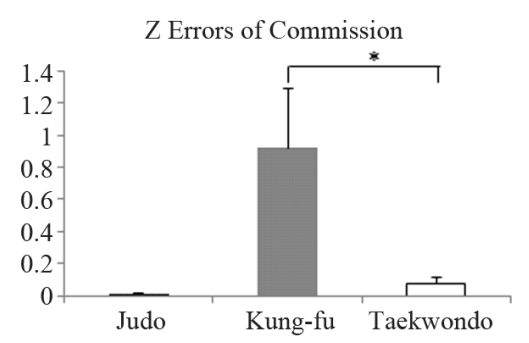

(a)

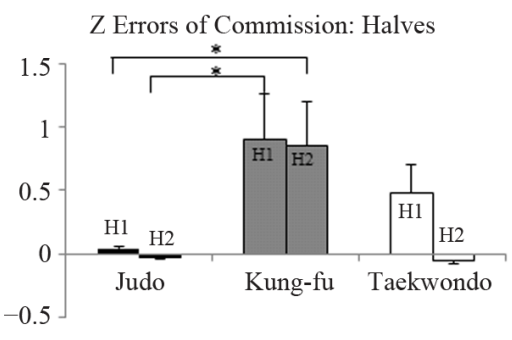

(b)

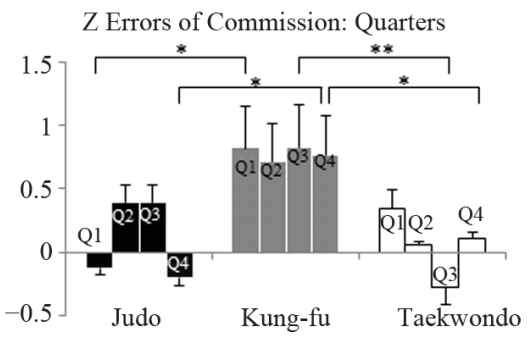

(c)

$$
\begin{aligned}
& * p \leq .05 \\
& * k \leq .01
\end{aligned}
$$

Figure 2.

$\mathrm{Z}$ scores for errors of commission for totals (a), halves (b) and quarters (c) in each group. Significant differences between groups are marked.

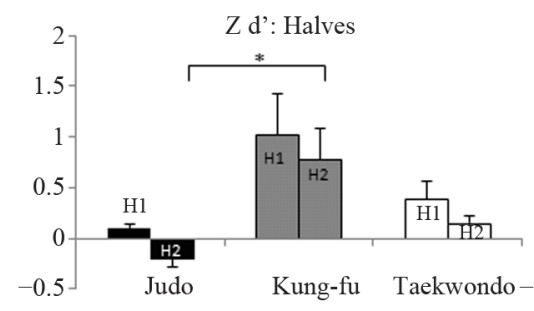

(a)

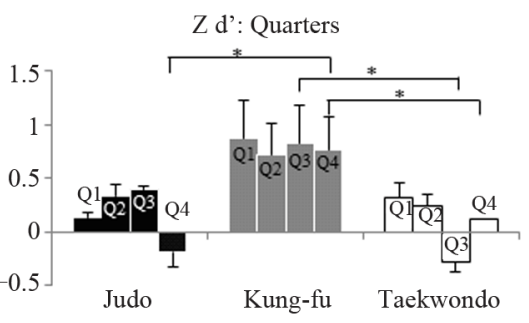

(b)

$$
\begin{aligned}
& " p \leq .05 \\
& * * \leq .01
\end{aligned}
$$

Figure 3.

$\mathrm{Z}$ scores for d' for halves (a) and quarters (b) in each group. Significant differences between groups are marked

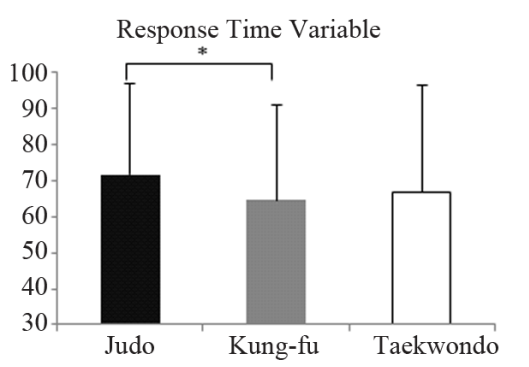

(a)
Response Time Variable: Quarters

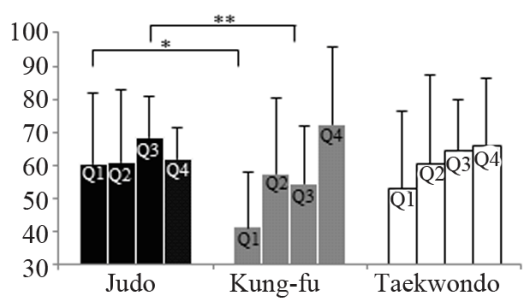

(b)

$$
\begin{aligned}
& { }^{*} \mathrm{p} \leq 0.05 \\
& { }^{*} \mathrm{p}<0.01
\end{aligned}
$$

Figure 4.

Response time variability for totals (a) and quarters (b) in each group. Significant differences between groups are marked. 
how perceptual and cognitive processes are improved as a result of sports practice. Expert athletes have shown better performance than beginners on cognitive tests (Fontani \& Lodi, 2002; Hack, Memmert, \& Rupp, 2009; Hamon \& Seri, 1989; Radlo, Janelle, Barba, \& Frehlich, 2001; Taliep et al., 2008). However, differences in cognitive processes among athletes of different athletic disciplines have been studied less frequently. Therefore, the aim of the present study was to compare athletes from different martial arts disciplines (judo, kung-fu and taekwondo) in the same methodological category to identify patterns of attentional subcomponents and to determine whether these patterns vary across martial arts disciplines.

We observed behavioural differences in TOVA among athletes who practice different disciplines. Although all participants showed scores within normal limits, kung-fu athletes showed better inhibition ability (indicated by fewer commission errors) and less response time variability and performance decrement (indicated by better d' scores) on the test than judo or taekwondo athletes. These results are consistent with previous studies that found that taekwondo athletes who were administered the Test of Psychological Traits for yield (PAR-P1) showed lower scores in psychological variables (motivation, attention, emotional sensitivity, imagination, positive attitude and challenge) than the normative database (Carazo \& Araya, 2010). Other findings for judo athletes (Ruiz, 2005) reported lower scores in emotional stability, which was defined as emotional control and impulse control in the BFQ questionnaire of personality. A higher variability for this dimension was related to gender and sport age. These findings are consistent with our results, in which taekwondo and judo showed lower scores than kung-fu for different variables of attention.

Kung-fu training characteristics likely improve attentional capacity more than training in the judo and taekwondo disciplines. This effect could be related to the greater dedication demanded by kung-fu training as well as the martial art's promotion of discipline, self-control and meditation. It has been demonstrated that individuals who meditate show increased capacity for self-regulation and emotional control than those who do not meditate. These findings have been supported by neuroimaging techniques, and individuals who meditate have shown increased activation relative to non-meditators in the prefrontal cortex and anterior cingulate cortex. Thus, this pattern of brain activation has been related to self-control (Baerentsen, Hartvig, Stokilde-Jorgensen, \& Mammen, 2001; Barinaga, 2003; Brefczynski-Lewis, Lutz, Schaefer, Levinson, \& Davidson, 2007; Bush, Luu, \& Posner, 2000; Cerf-Ducastel, Ven de Moortele, MacLeod, Le Bihan, \& Faurion, 2001; Dunn, Hartigan, \& Mikulas, 1999; Gusnard, Akbudak, Shulman, \& Raichle, 2001; Holzel et al., 2007). Therefore, kung-fu athletes may be defined as having more efficient self-inhibition than judo or taekwondo athletes.

\section{Conclusion}

Our results show differences in the variables of attention between martial arts disciplines. Kung-fu athletes showed better inhibition ability than judo or taekwondo athletes. Kung-fu training improves attention ability more than the other two disciplines, and this effect can be explained by the greater dedication demanded by kung-fu training as well as kung-fu's promotion of discipline, self-control and meditation.

Even though the permutation statistical method is ideal for showing differences between groups with very small samples, but it is important to note a greater effect by increasing the sample. Future studies with a large number of participants would be necessary. Also, we propose the integration of more disciplines to define the attentional characteristics in different sports, which is important in offering useful information to trainers and athletes in order to improve the educational processes of their training plans.

\section{Acknowledgements}

This research was supported by Programa de Apoyo a Proyectos de Investigación e Innovación Tecnológica (PAPIIT IN205212). The authors are grateful for the participant's cooperation in this study. The authors also acknowledge the technical assistance of Leonor Casanova, Lourdes Lara and Héctor Belmont.

\section{REFERENCES}

Abernethy, B., \& Russell, D. G. (1987). Expert-novice differences in an applied selective attention task. Journal of Sport Psychology, 9, 326345.

Anshel, M. H., \& Payne, J. M. (2006). Application of sport psychology for optimal performance in martial arts. In J. Dosil (Ed.), The sport psychologist's handbook. A guide for sport-specific performance enhancement (pp. 353-374). Inglaterra: John Wiley \& Sons.

Baerentsen, K. B., Hartvig, N. V., Stokilde-Jorgensen, H., \& Mammen, J. (2001). Onset of meditation explored with fMRI. Neuroimage, 13, S297-S297. doi:10.1016/S1053-8119(01)91640-4

Barinaga, M. (2003). Buddhism and neuroscience. Studying the well-trained mind. Science, 302, 44-46.

doi:10.1126/science.302.5642.44

Brefczynski-Lewis, J. A., Lutz, A., Schaefer, H. S., Levinson, D. B., \& Davidson, R. J. (2007). Neural correlates of attentional expertise in long-term meditation practitioners. Proceedings of the National Academy of Sciences of the United States of America, 104, 1148311488. doi:10.1073/pnas.0606552104

Burle, B., Possamaï, C., Vidal, F., Bonnet, M., \& Hasbroucq, T. (2002). Executive control in the Simon effect: An electromyographic and distributional analysis. Psychological Research, 66, 324-336. doi:10.1007/s00426-002-0105-6

Bush, G., Luu, P., \& Posner, M. I. (2000). Cognitive and emotional influences in anterior cingulate cortex. Trends in Cognitive Sciences, 4, 215-222. doi:10.1016/S1364-6613(00)01483-2

Carazo, V. P., \& Araya, V. G. A. (2010). Profile of psychological traits to sport performance in males and females taekwondo practitioners. Revista Iberoamericana de Psicología del Ejercicio y el Deporte, 5, 253-265.

Cerf-Ducastel, B., Ven de Moortele, P. F., MacLeod, P., Le Bihan, D., \& Faurion, A. (2001). Interaction of gustatory and lingual somatosensory perceptions at the cortical level in the human: A functional magnetic resonance imaging study. Chemical Senses, 26, 371-383. doi: $10.1093 /$ chemse/26.4.371

Del-Monte, L. (2005). Relationship between concentration of attention ability and sport performance in female judo athletes of national team from Cuba. Lecturas: Educación Física y Deportes. Revista Digital, 87, 1 .

Dunn, B. R., Hartigan, J. A., \& Mikulas, W. L. (1999). Concentration and mindfulness meditations: Unique forms of consciousness? Applied Psychophysiology and Biofeedback, 24, 147-165. doi:10.1023/A:1023498629385

Fontani, G., \& Lodi, L. (2002). Reactivity and event-related potentials in attentional tests: Effect of training. Perceptual and Motor Skills, 94, 817-833.

Fontani, G., Lodi, L., Felici, A., Migliorini, S., \& Corradeschi, F. (2006). Attention in athletes of high and low experience engaged in different open skill sports. Perceptual and Motor Skills, 102, 791- 


\section{J. SÁNCHEZ-LÓPEZ ET AL.}

805. doi:10.2466/pms.102.3.791-805

Galan, L., Biscay, R., Rodriguez, J. L., Perez-Abalo, M. C., \& Rodriguez, R. (1997). Testing topographic differences between event related brain potentials by using non-parametric combinations of permutation tests. Electroencephalography and Clinical Neurophysiology, 102, 240-247. doi:10.1016/S0013-4694(96)95155-3

Gusnard, D. A., Akbudak, E., Shulman, G. L., \& Raichle, M. E. (2001). Medial prefrontal cortex and self-referential mental activity: Relation to a default mode of brain function. Proceedings of the National Academy of Sciences of the United States of America, 98, 4259-4264. doi:10.1073/pnas.071043098

Hack, J., Memmert, D., \& Rupp, A. (2009). Attentional mechanisms in sports via brain-electrical event-related potentials. Research Quarterly for Exercise \& Sport, 80, 727-738.

Hamon, J. F., \& Seri, B. (1989). Cortical reactivity during reaction time tests in sprinters. Clinical Neurophysiology, 19, 109-122. doi:10.1016/S0987-7053(89)80051-6

Holzel, B. K., Ott, U., Hempel, H., Hack1, A., Wolf, K., Stark, R., \& Vaitl, D. (2007). Differential engagement of anterior cingulate and adjacent medial frontal cortex in adept meditators and non-meditators. Neuroscience Letters, 421, 16-21. doi:10.1016/j.neulet.2007.04.074

Lakes, K. D., \& Hoyt, W. T. (2004). Promoting self-regulation through school-based martial arts training. Applied Developmental Psychology, 25, 283-302. doi:10.1016/j.appdev.2004.04.002

Leark, R. A., Greenberg, L. M., Kindschi, C. L., Dupuy, T. R., \& Hughes, S. J. (2007). T.O.V.A. professional manual. Test of variables of attention continuous performance test. Los Alamitos, CA: T.O.V.A Company.

Nougier, V., \& Rossi, B. (1999). The development of expertise in the orientation of attention. International Journal of Sport Psychology, 30, 246-260.

Posner, M. I. (2004). Cognitive neuroscience of attention. New York: The Gilford Press.

Posner, M. I., \& Petersen, S. E. (1990). The attention system of the human brain. Annual Review of Neuroscience, 13, 25-42. doi:10.1146/annurev.ne.13.030190.000325

Radlo, S. J., Janelle, C. M., Barba, D. A., \& Frehlich, S. G. (2001) Perceptual decision making for baseball pitch recognition: Using P300 latency and amplitude to index attentional processing. Research Quarterly for Exercise and Sport, 72, 22-31. doi: $10.1080 / 02701367.2001 .10608928$

Ridderinkhof, K. R. (2002). Micro- and macro-adjustments of task set: Activation and suppression in conflict tasks. Psychological Research, 66, 312-323. doi:10.1007/s00426-002-0104-7

Rodríguez, R. J. P. (2003). Compendio historico de la actividad física y el deporte. México: Masson.

Ruiz, B. R. (2005). Análisis de las diferencias de personalidad en el deporte de judo a nivel competitivo en función de la variable sexo y categoría de edad deportiva. Cuadernos de Psicología del Deporte, 5 , 29-48.

Taliep, M. S., Gibson, A. S. C., Gray, J., van der Merwe, L., Vaughan, C. L., Noakes, T. D., \& John, L. R. (2008). Event-related potentials, reaction time, and response selection of skilled and less-skilled cricket batsmen. Perception, 37, 96-105. doi:10.1068/p5620

Williams, A. M., Davids, K., \& Williams, J. G. (1999). Visual perception and action in sport. London: E \& FN Spon.

Williams, A. M., \& Grant, A. (1999). Training perceptual skill in sport. International Journal of Sport Psychology, 30, 194-220. 